seems that our patient had a low-grade Aspergillus species infection in the sequestered lung segment in the right paratracheal region. Because the mass persisted despite itraconazole therapy, excision was requested.

So far as we are aware, this is a unique case of pulmonary sequestration presenting as a right paratracheal mass with Aspergillus species infection. During literature review, we came across a case of pulmonary sequestration presenting as a retroperitoneal mass described by Nelson, Blum, and Cook, ${ }^{4}$ suggesting that pulmonary sequestration can manifest in unusual forms.

\section{References}

1. Pryce DM. Lower accessory pulmonary artery with intralobar sequestration of lung: a report of seven cases. J Pathol. 1946;58:457-67.

2. Khalil KG, Kilman JW. Pulmonary sequestration. J Thorac Cardiovasc Surg. 1975;70:928-37.

3. Schwartz MZ, Ramachandran P. Congenital malformations of the lung and mediastinum - a quarter century of experience from a single institution. J Pediatr Surg. 1997;32:44-7.

4. Nelson JB, Blum MD, Cook WA. Retroperitoneal pulmonary sequestration: a rare congenital anomaly in a 71 year old man. $J$ Urol. 1994;152(suppl):2341-3.

\title{
THORACIC SURGERY FOUNDATION FOR RESEARCH AND EDUCATION 2005 RESEARCH AWARD RECIPIENTS
}

\section{TSFRE RESEARCH FELLOWSHIP}

Madison C. Cuffy, MD—“"The Role of Indoleamine 2,3 Dioxygenase on Modulating Immune Responses in Inflammatory Arterial Diseases," Yale University School of Medicine

Andrew J. Kaufman, MD_-"Functional Analysis of Squamous Cell Carcinoma Related Oncogene (SCCRO) in the Sonic Hedgehog Pathway," Memorial Sloan-Kettering Cancer Center

Tom C. Nguyen, MD_-"Biomechanics of the Cardiac Support Device in Heart Failure: New Answers to an Old Problem," Stanford University

Hisasha Sahara, MD_-"Indirect Recognition of Collagen (Type V) in the Pathogenesis of Lung Allograft Rejection," Massachusetts General Hospital, Harvard Medical School

\section{TSFRE RESEARCH GRANT}

Ara A. Vaporciyan, MD_"Effect of Inflammatory Gene Polymorphism in the Development of Atrial Fibrillation After Pulmonary Resection," University of Texas, M.D. Anderson Cancer Center

\section{NINA STARR BRAUNWALD RESEARCH FELLOWSHIP}

Barbara L. Robinson, MD—“The Stunned Heart and Cardiac Surgery: Apoptosis/Necrosis and the Role of Heat Shock Proteins,” Boston Children's Hospital 